\title{
Higher $\mathbf{N}$ stage and serum ferritin, but lower serum albumin levels are associated with distant metastasis and poor survival in patients with nasopharyngeal carcinoma following intensity- modulated radiotherapy
}

\author{
Xiaoqian Chen ${ }^{1}$, Xianfeng Long ${ }^{1}$, Zhongguo Liang ${ }^{1}$, Hao Lei ${ }^{2}$, Ling $\mathrm{Li}^{1}$, Song $\mathbf{Q u}^{1}$ \\ and Xiaodong Zhu ${ }^{1}$ \\ ${ }^{1}$ Department of Radiation Oncology, Cancer Hospital of Guangxi Medical University, Nanning 530021, China \\ ${ }^{2}$ Department of Radiation Oncology, Hubei Cancer Hospital, Wuhan 430079, China \\ Correspondence to: Xiaodong Zhu, email: zhuxdonggxmu@126.com \\ Keywords: nasopharyngeal carcinoma, serum albumin, serum ferritin, distant metastasis, intensity-modulated radiotherapy \\ Received: January 21, $2017 \quad$ Accepted: March 29, $2017 \quad$ Published: April 25, 2017 \\ Copyright: Chen et al. This is an open-access article distributed under the terms of the Creative Commons Attribution License 3.0 \\ (CC BY 3.0), which permits unrestricted use, distribution, and reproduction in any medium, provided the original author and source \\ are credited.
}

\section{ABSTRACT}

Purpose: To evaluate the potential risk factors for distant metastasis of nasopharyngeal carcinoma in Chinese patients following standard intensity-modulated radiotherapy and chemotherapy.

Methods: The potential risk factors for distant metastasis in 622 patients with newly-diagnosed primary nasopharyngeal carcinoma following standard radiotherapy and chemotherapy were evaluated retrospectively by stratification, univariate and multivariate analyses. The 5-year overall survival, distant metastasis-free survival, local recurrence-free survival and progression-free survival rates were determined.

Results: Univariate and multivariate analyses indicated that N2-3 stage, serum ferritin $>300 \mu \mathrm{g} / \mathrm{L}$ and serum albumin $<42 \mathrm{~g} / \mathrm{L}$ were independent risk factors for distant metastasis of nasopharyngeal carcinoma $(P<0.001, P=0.013, P=0.002$, respectively). A risk prediction model was developed as follows: 1 ) low-risk group: 0-1 risk factor; and 2) high-risk group: 2-3 risk factors. Compared with low-risk group, the high-risk group had significantly lower 5-year distant metastasis-free survival (76.4\% vs. $89.6 \%, P<0.001$ ), overall survival ( $76 \%$ vs. $85.9 \%, P<0.001$ ), local recurrence-free survival $(88 \%$ vs. $92.4 \%, P=0.029)$ and progression-free survival rates $(68.2 \%$ vs. $83.7 \%, P<0.001)$. In the high-risk group, patients with three risk factors had the lowest distant metastasis-free survival rate $(P=0.036)$.

Conclusions: Combination of higher $\mathbf{N}$ stage, serum ferritin and lower serum albumin levels may be valuable for predicting distant metastasis of nasopharyngeal carcinoma patients following standard intensity-modulated radiotherapy and chemotherapy.

\section{INTRODUCTION}

Nasopharyngeal carcinoma (NPC) is a malignant tumor with distinct regional distribution. NPC is a relatively rare disease in Europe and the United States with an incidence rate of $<1 \%$. However, it is endemic in Southeast Asia, especially in South China [1, 2]. NPC is characterized by a poorly differentiated tumor at a complex anatomical location and easy invasion of adjacent organs. NPC is sensitive to radiotherapy, and NPC patients are usually treated by radiotherapies. While the therapeutic efficacy of radiotherapies for NPC patients, particularly with intensity-modulated radiotherapy (IMRT), has been recently improved following the advance in radiotherapy technology and equipment, the distant metastasis (DM) remains the major challenge for long-term survival [3-6]. Actually, even after combination of IMRT with neoadjuvant chemotherapy, concurrent or adjuvant 
chemotherapy, the DM rate still reaches about 20\% [7-9]. Therefore, identification of DM relevant risk factors will be of great significance in reduction and prevention of DM in NPC patients and improving their overall survival (OS).

Currently, the TNM staging system has been demonstrated to have prognostic value and is used for guiding treatment strategies. However, even within the same TNM stage, varying OS periods and different risks for DM among NPC patients have been observed [10, 11]. Thus, simple TNM stage may be insufficient and ineffective to predict DM and discovery of other risk factors is necessary to build a more efficient prediction model to evaluate the DM risks in NPC patients.

Recent studies have showed that factors affecting the outcomes of cancer patients include the tumor characteristics and the host response factors [12-14]. The levels of serum albumin (ALB) are closely related to the degrees of malnutrition [15], affected by inflammatory responses [16], and associated with a poorer prognosis in cancer patients $[17,18]$. In recent years, the levels of serum ALB are often combined with other inflammatory response indexes to evaluate prognosis in NPC $[19,20]$.

Serum ferritin (SF) is the primary intracellular iron-storage protein, regulating many physiological and pathological processes. Elevated SF levels have been recognized as a predictor of treatment response and are associated with poor prognosis in various malignancies, such as pancreatic cancer, non-small cell lung cancer, hepatocellular carcinoma and breast cancer [21-24]. However, there is rare study on the association between the levels of SF and DM in NPC patients [25].

The present study aimed to detect the potential risk factors for DM in Chinese patients with NPC and evaluated the prognostic value of abnormal levels of serum ALB, SF and other selective markers for DM besides the TNM stage in NPC patients following IMRT and chemotherapy.

\section{RESULTS}

\section{Patient characteristics and treatment outcomes}

To determine the potential risk factors for DM, 622 patients with NPC were recruited and treated with standard IMTR and chemotherapy. Their demographic and clinical characteristics are shown in Table 1 . Those patients were characterized by higher frequency of male, patients with NPC at advanced stages of Union for International Cancer Control/ American Joint Committee on Cancer (UICC/ AJCC), normal blood hemoglobin $(\mathrm{Hb})$, but lower serum lactate dehydrogenase (LDH) and abnormal lower blood platelet (PLT) counts (Table 1). Patients were followed up with a median follow-up period of 43 months (range from 1 to 95 months), except for 12 patients, who were lost to follow-up. During the follow-up period, $18.3 \%$ of patients $(114 / 622)$ had died (106 cases died of tumor, 2 cases died of severe nasopharyngeal bleeding and 6 cases died of other diseases), and $23 \%$ of patients (143/622) experienced tumor progression, including $9.5 \%(59 / 622)$ with local or regional recurrence and $16.1 \%(100 / 622)$ with DM. The 5-year OS, distant metastasis-free survival (DMFS), local recurrentfree survival (LRFS) and progression-free survival (PFS) rates were $82.9 \%, 83.9 \%, 90.8 \%$ and $77.3 \%$, respectively.

\section{Prognostic factors for distant metastasis}

Stratification analyses indicated that the percentages of DM in the patients with NPC at UICC/AJCC T4, N2-3, higher UICC/AJCC stages, lower serum ALB or higher SF levels were significantly higher than those with lower UICC/AJCC T, lower N or UICC/AJCC stages, higher serum ALB or lower SF in this population $(P=0.012, P<$ $0.001, P<0.001, P=0.006$ and $P=0.018$, respectively, Table 1$)$. Univariate analysis revealed that NPC at T4 stage $(P=0.006)$, N2-3 stage $(P<0.001)$, serum ALB $<$ $42 \mathrm{~g} / \mathrm{L}(P=0.004)$ and $\mathrm{SF}>300 \mu \mathrm{g} / \mathrm{L}(P=0.022)$ were significantly risk factors associated with DM (Table 2$)$. Multivariate analysis further validated that N2-3 stage, serum ALB $<42 \mathrm{~g} / \mathrm{L}$ and $\mathrm{SF}>300 \mu \mathrm{g} / \mathrm{L}$ were independent risk factors for DM $(P<0.001, P=0.002, P=0.013$, respectively).

\section{Risk prediction model for distant metastasis and survival}

Patients were stratified by individual risk factors of $\mathrm{N}$ stage, serum ALB and SF, and the DMFS rates of patients with NPC at N2-3, serum ALB $<42 \mathrm{~g} / \mathrm{L}$ or SF $>300 \mu \mathrm{g} / \mathrm{L}$ were significantly lower than the corresponding patients without the specific risk (Figure 1, $P<0.001, P=0.003$ and $P=0.021$, respectively). Based on the three risk factors, a risk prediction model for DM in NPC patients was established. Patients were stratified into 1) low-risk group: 0-1 risk factor (355 patients); and 2) high-risk group: 2-3 risk factors (267 patients). The receiver operating characteristic (ROC) curves were used to evaluate the prognostic value of each risk factor and the risk prediction model (Figure 2). The 5-year DMFS, OS, LRFS and PFS rates of patients with high-risk were significantly lower than those with low-risk (76.4\% vs. $89.6 \%, P<0.001$ for DMFS; $76 \%$ vs. $85.9 \%, P<0.001$ for OS; $88 \%$ vs. $92.4 \%, P=0.029$ for LRFS; $68.2 \%$ vs. $83.7 \%$, $P<0.001$ for PFS, Figure 3).

In the high-risk group, there were 90 patients at N2-3 stage and ALB $<42 \mathrm{~g} / \mathrm{L}, 77$ patients at N2-3 stage and $\mathrm{SF}>300 \mu \mathrm{g} / \mathrm{L}, 40$ patients with $\mathrm{ALB}<42 \mathrm{~g} / \mathrm{L}$ and $\mathrm{SF}>300 \mu \mathrm{g} / \mathrm{L}$, and 60 patients with the three risk factors. There was a significant difference in the DMFS rates among these four groups $(P=0.036$, Figure 4$)$. Among them, the DMFS rate of patients at N2-3 stage and SF $>$ $300 \mu \mathrm{g} / \mathrm{L}$ had the best survival value, followed by patients at N2-3 stage and ALB $<42 \mathrm{~g} / \mathrm{L}$, and then the patients with $\mathrm{ALB}<42 \mathrm{~g} / \mathrm{L}$ and $\mathrm{SF}>300 \mu \mathrm{g} / \mathrm{L}$, while the patients with three risk factors had the worst survival value. 
Table 1: The demographic and clinical characteristics of patients.

\begin{tabular}{|c|c|c|c|}
\hline Clinical characteristics & Case numbers $(\%)$ & DM (\%) & $P$ values \\
\hline All cases & 622 & 100 & \\
\hline Age (years) & & & 0.232 \\
\hline$\geq 44$ & $333(53.53)$ & $59(17.71)$ & \\
\hline$<44$ & $289(46.47)$ & $41(14.18)$ & \\
\hline Gender & & & 0.521 \\
\hline Male & $463(74.44)$ & $77(16.63)$ & \\
\hline Female & $159(25.56)$ & $23(14.47)$ & \\
\hline 2010UICC/AJCC T category & & & 0.012 \\
\hline $\mathrm{T} 1-3$ & $433(69.61)$ & $59(13.63)$ & \\
\hline $\mathrm{T} 4$ & $189(30.39)$ & $41(21.69)$ & \\
\hline 2010UICC/AJCC N category & & & $<0.001$ \\
\hline N0-1 & $287(46.14)$ & $27(9.41)$ & \\
\hline $\mathrm{N} 2-3$ & $335(53.86)$ & $73(21.79)$ & \\
\hline 2010UICC/AJCC stage & & & $<0.001$ \\
\hline I & $13(2.10)$ & $0(0)$ & \\
\hline II & $120(19.29)$ & $8(6.67)$ & \\
\hline III & $277(44.53)$ & $45(16.25)$ & \\
\hline IVA-B & $212(34.08)$ & $47(22.17)$ & \\
\hline $\mathrm{Hb}(\mathrm{g} / \mathrm{L})$ & & & 0.208 \\
\hline$\geq 120$ & $546(87.78)$ & $84(15.38)$ & \\
\hline$<120$ & $76(12.22)$ & $16(21.05)$ & \\
\hline $\operatorname{PLT}(\mathrm{k} / \mathrm{cc})$ & & & 0.418 \\
\hline$>300$ & $107(17.20)$ & $20(18.69)$ & \\
\hline$\leq 300$ & $515(82.80)$ & $80(15.53)$ & \\
\hline $\operatorname{ALB}(g / L)$ & & & 0.006 \\
\hline$\geq 42$ & $345(55.47)$ & $43(12.46)$ & \\
\hline$<42$ & $277(44.53)$ & $57(20.58)$ & \\
\hline LDH (U/L) & & & 0.848 \\
\hline$>245$ & $59(9.49)$ & $10(16.95)$ & \\
\hline$\leq 245$ & $563(90.51)$ & 90 (15.99) & \\
\hline $\mathrm{SF}(\mu \mathrm{g} / \mathrm{L})$ & & & 0.018 \\
\hline$>300$ & $251(40.35)$ & $51(20.32)$ & \\
\hline$\leq 300$ & $371(59.65)$ & $49(13.21)$ & \\
\hline
\end{tabular}

Hb: hemoglobin, PLT: platelet, ALB: albumin, LDH: lactate dehydrogenase, SF: serum ferritin 
Table 2: The risk factors are associated with distant metastasis in NPC patients.

\begin{tabular}{|c|c|c|c|c|c|c|}
\hline \multirow[t]{2}{*}{ Variables } & \multicolumn{3}{|c|}{ Univariate analysis } & \multicolumn{3}{|c|}{ Multivariate analysis } \\
\hline & HR & $95 \%$ CI & $P$ value & HR & $95 \% \mathrm{CI}$ & $P$ value \\
\hline $\begin{array}{l}\text { Age, years ( } \geq 44 \text { vs } \\
<44)\end{array}$ & 1.322 & $0.888 \sim 1.970$ & 0.170 & & & \\
\hline $\begin{array}{l}\text { Gender (Male vs } \\
\text { Female) }\end{array}$ & 1.190 & $0.747 \sim 1.895$ & 0.465 & & & \\
\hline $\begin{array}{l}\text { T staging (T4 vs } \\
\text { T1-3) }\end{array}$ & 1.756 & $1.179 \sim 2.616$ & 0.006 & & & \\
\hline $\begin{array}{l}\text { N staging (N2-3 vs } \\
\text { N0-1) }\end{array}$ & 2.507 & $1.612 \sim 3.899$ & $<0.001$ & 2.423 & $1.555 \sim 3.775$ & $<0.001$ \\
\hline $\begin{array}{l}\mathrm{Hb}, \mathrm{g} / \mathrm{L}(<120 \text { vs } \\
\geq 120)\end{array}$ & 1.407 & $0.824 \sim 2.401$ & 0.211 & & & \\
\hline $\begin{array}{l}\text { PLT, } \mathrm{k} / \mathrm{cc}(>300 \mathrm{vs} \\
\leq 300)\end{array}$ & 1.262 & $0.773 \sim 2.060$ & 0.352 & & & \\
\hline $\begin{array}{l}\text { ALB, g/L ( }<42 \text { vs } \\
\geq 42)\end{array}$ & 1.798 & $1.210 \sim 2.671$ & 0.004 & 1.774 & $1.182 \sim 2.664$ & 0.002 \\
\hline $\begin{array}{l}\mathrm{LDH}, \mathrm{U} / \mathrm{L}(>245 \text { vs } \\
\leq 245)\end{array}$ & 1.125 & $0.585 \sim 2.162$ & 0.725 & & & \\
\hline $\begin{array}{l}\mathrm{SF}, \mu \mathrm{g} / \mathrm{L}(>300 \mathrm{vs} \\
\leq 300)\end{array}$ & 1.583 & $1.069 \sim 2.342$ & 0.022 & 1.647 & $1.111 \sim 2.442$ & 0.013 \\
\hline
\end{tabular}

Abbreviations: Hb: hemoglobin, PLT: platelet, ALB: albumin, LDH: lactate dehydrogenase, SF: serum ferritin

\section{DISCUSSION}

Local recurrence and DM are the main causes of mortality in M0 stage NPC patients following standard IMRT and chemotherapy. The IMRT is the first line of therapy for NPC and has significantly improved recurrence-free survival [26, 27], although DM remains the primary factor for mortality. In this study, we evaluated the potential risks for DM of NPC. We found that patients at N2-3 stage, $\mathrm{SF}>300 \mu \mathrm{g} / \mathrm{L}$ and serum ALB $<42 \mathrm{~g} / \mathrm{L}$ were independent risk factors of DM. Generally, T stage is closely related to local relapse, while higher $\mathrm{N}$ stage is connected with DM of NPC [28, 29]. Higher N stage was a risk factor for DM of NPC, consistent with previous observations [7, 30-32]. It is possible that NPC at an advanced N stage may have a higher risk for micrometastasis, which may be difficult to be overcome by an increase of irradiated dose to tumor targets by IMRT, leading to recurrence and DM [7].

In the present study, we found that NPC patients with lower serum ALB levels and higher SF were associated with an increased risk for DM, leading to a significantly lower DMFS rates in this population. Serum ALB is usually used to evaluate the long-term nutritional status and is affected by systemic inflammatory responses because ALB can promote wound healing and hormone synthesis [33]. Our findings were consistent with previous observations that lower serum ALB increases the risk of tumor progression and poor survival in patients with various cancers [34-36]. In NPC patients, the major pathologic type is undifferentiated non-keratinizing carcinoma, formerly known as "lymphoepithelial carcinoma". This pathologic type of NPC contains numerous lymphocytes within the tumor, which indicates that inflammation may promote the development and progression of NPC [20]. Furthermore, the lower ALB and malnutrition may weaken the ability of patients to confront stress and anticancer therapy, hence deteriorating the life quality and survival [37]. Indeed, we found that NPC patients with lower serum ALB had significantly lower DMFS rate. Hence, correction of lower serum ALB may support the survival of patients with NPC.

$\mathrm{SF}$ is the best single marker to reflect the iron storage in vivo $[38,39]$. As an ion transporter, iron participates in lipid peroxidation, leading to DNA damage [40, 41]. Previous studies have shown that excessive iron can suppress the function of CD4+ T cells [42], as well as the tumorcidal activity of macrophagocytes and monocytes $[43,44]$, but increase the numbers and activities of suppressor CD8+ T cells, impairing anti-tumor responses $[45,46]$. The imbalance of immune function, together with higher plasma concentration of Epstein-Barr virus 
A

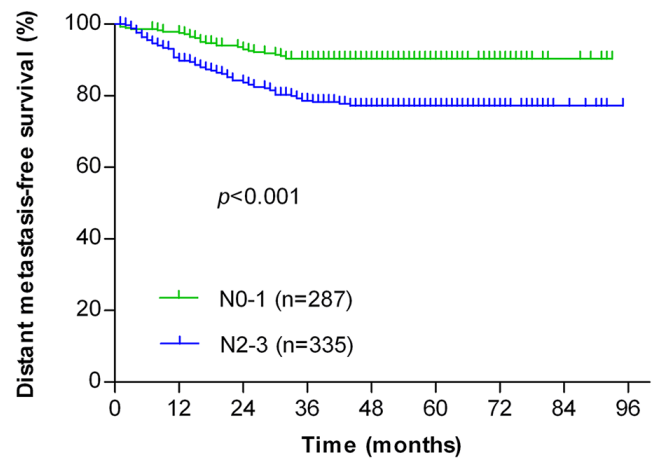

C

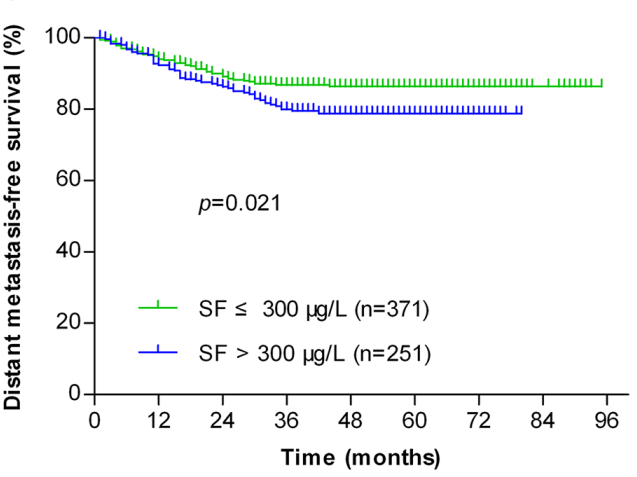

B

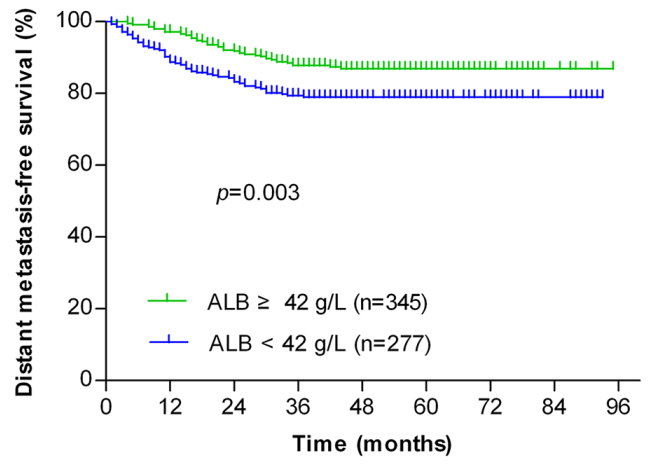

Figure 1: Kaplan-Meier analysis of the distant metastasis-free survival for all NPC patients $(n=622)$ after being stratified by $\mathrm{N}$ stage (A), serum albumin (B) and serum ferritin (C).

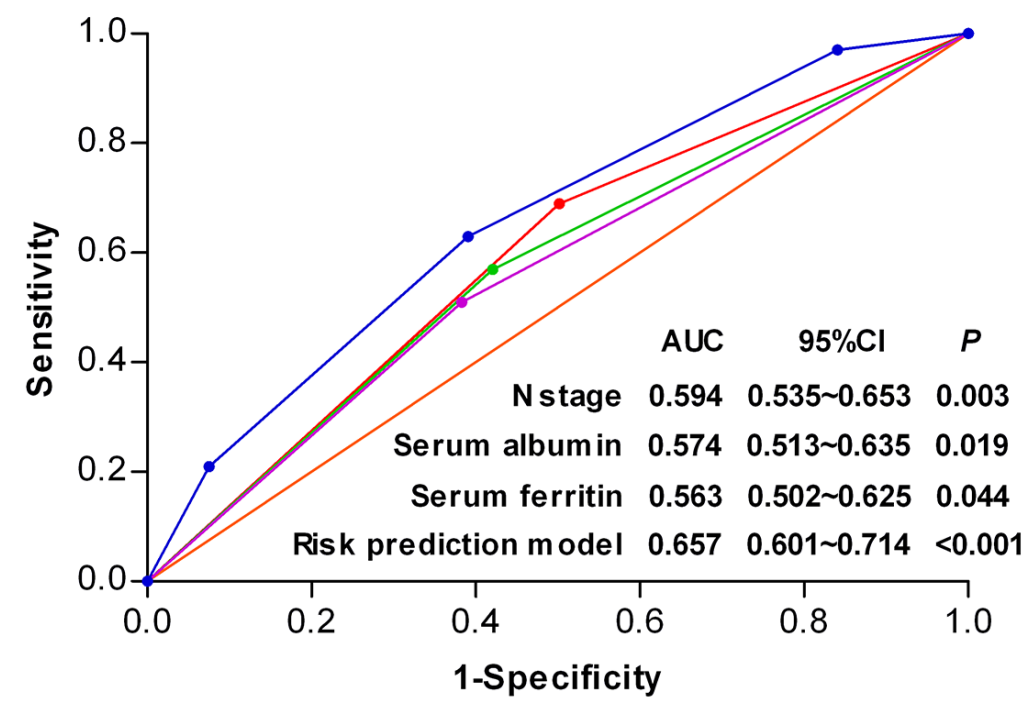

\begin{tabular}{|c|c|c|}
\hline$\rightarrow \quad N$ stage & $\rightarrow$ & Risk prediction model \\
\hline$\rightarrow$ Serum albumin & $\longrightarrow$ & Reference \\
\hline
\end{tabular}

Figure 2: Receiver operating characteristic curves for distant metastasis in NPC patients $(n=622)$ based on the individual risk factors and risk prediction model. 
A

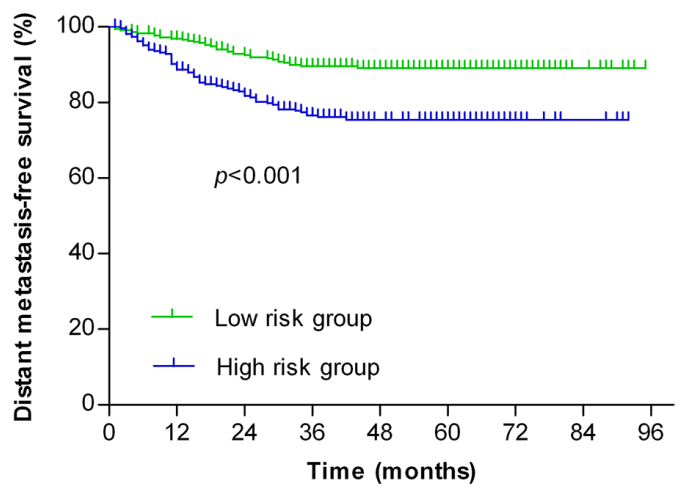

C

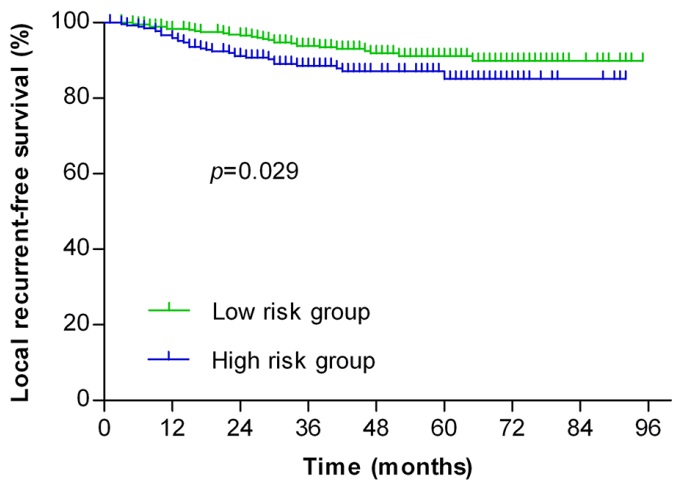

B

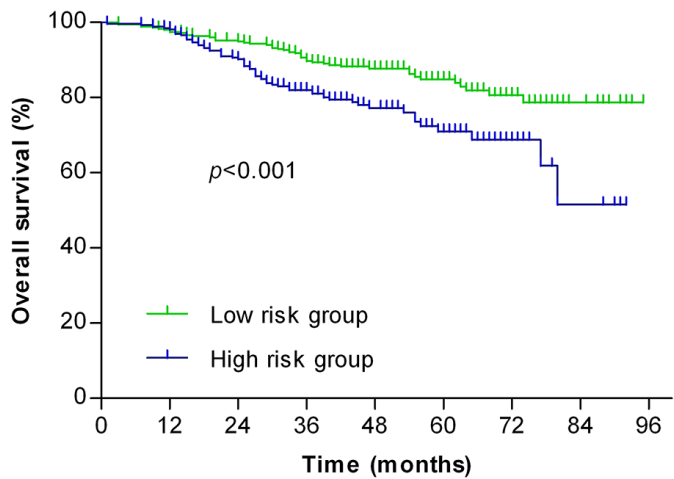

D

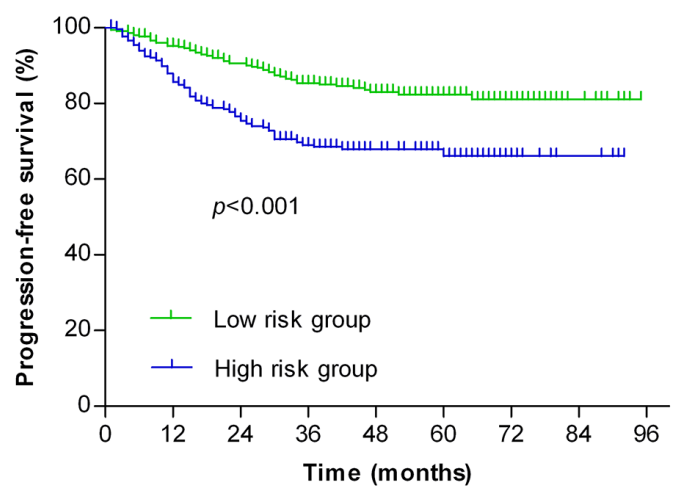

Figure 3: Stratification analysis of the survival of NPC patients. The patients were stratified into the low-risk ( $\mathrm{n}=355$ ) and highrisk ( $\mathrm{n}=267$ ) groups using the distant metastasis risk prediction model. The distant metastasis-free survival (A), overall survival (B), local recurrent-free survival (C) and progression-free survival (D) were statistically analyzed.

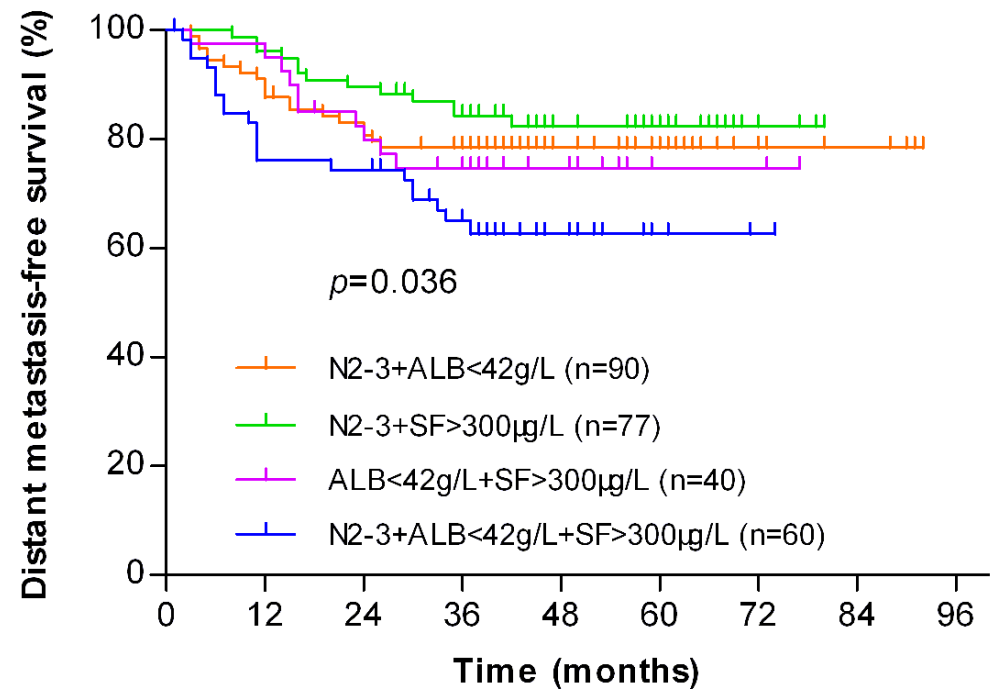

Figure 4: Kaplan-Meier analysis of the distant metastasis-free survival (DMFS) for NPC patients in the high-risk $(n=267)$ group stratified by combinations of different risk factors. The DMFS rate of patients at N2-3 stage and $\mathrm{SF}>300 \mu \mathrm{g} / \mathrm{L}$ $(\mathrm{n}=77)$ had the best value, followed by patients at N2-3 stage and ALB $<42 \mathrm{~g} / \mathrm{L}(\mathrm{n}=90)$, and then the patients with ALB $<42 \mathrm{~g} / \mathrm{L}$ and $\mathrm{SF}>$ $300 \mu \mathrm{g} / \mathrm{L}(\mathrm{n}=40)$, while the patients with three risk factors $(\mathrm{n}=60)$ had the worst survival value $(P=0.036)$. 
DNA, may be associated with an increased risk for DM in NPC patients [47-49]. Ferritin is a cytoplasm protein and responsible for regulating iron store and load. Currently, there is no clear information on what causes high levels of SF in a condition without iron overload [50]. First, the damage of red blood cells can release ferritin, leading to an increase in the levels of SF. Second, the tumorassociated oxidative stress and inflammation, such as chronic infection, can damage different types of cells to release ferritin to increase SF levels in a hemolysisindependent manner [51]. In addition, hepatic dysfunction and mucositis may also increase the release of ferritin to increase SF levels [52].We are interested in further investigating what factors are associated with higher levels of SF in NPC patients.

The TNM staging system has been used for prognosis and treatment guidance in NPC patients, but the efficacy of its prognosis of DM is low. For example, patients with NPC at stage T1N2M0 may have a higher risk of DM than those at T3N0M0 stage, and they may require more aggressive treatments to reduce DM. In addition, the physical condition in individual patients also affects DM following initial treatments. Hence, combination of multiple factors to predict the risks of DM may valuable in management of NPC patients. Indeed, we combined independent risk factors of higher $\mathrm{N}$ stage, higher levels of SF and lower levels of serum ALB for DM to establish a predictive model. Stratification analysis indicated that NPC patients at a low-risk had significantly higher OS, DMFS, LRFS and PFS rates than those at a high-risk while patients with three risk factors had the poorest DMFS. Therefore, this prognostic model may be superior to the TNM classification system for evaluating DM of NPC.

We recognized that this study had limitations, such as a relatively smaller sample size, a single-institution retrospective analysis, which may have a selection bias to a certain extent. A prospective study will be necessary to confirm the reliability of this prognostic model.

In conclusion, our data indicated that a higher $\mathrm{N}$ stage, SF and lower levels of serum ALB were independent risk factors associated with lower OS, DMFS, LRFS and PFS rates in NPC patients. The risk prediction model based on these three risk factors may be valuable for physicians to evaluate potential risks of DM and to use for personalized medicine in NPC patients.

\section{MATERIALS AND METHODS}

\section{Patients}

A total of 622 NPC patients that had been treated with standard IMRT and chemotherapy at the Cancer Hospital of Guangxi Medical University were recruited from 2157 NPC patients between January 2007 and July 2012 and were analyzed retrospectively. The inclusion criteria included individuals with histologically confirmed
NPC in nasopharyngeal biopsied sample; no evidence of DM; no previous history of a malignancy or other concomitant malignant disease; no previous treatment for NPC; Karnofsky performance status of 70 or more. Individual NPC patients, who did not meet the criteria, were excluded. Written informed consent was obtained from individual patients and the experimental protocol was approved by the Ethics Committee of the Cancer Hospital of Guangxi Medical University (Nanning, China).

\section{Laboratory measurements}

The levels of blood Hb, PLT, serum ALB, LDH and ferritin in individual patients were measured before radiotherapy. The levels of blood $\mathrm{Hb}$ and PLT were measured using an automatic hematology analyzer (LH750, Beckman Counlter, USA). The levels of serum ALB, LDH and ferritin were measured using an automatic biochemical analyzer (7600-020, Hitachi HighTechnologies, Japan).

\section{Radiotherapy}

According to International Commission on Radiation Units and Measurements Reports 50 and 62, the target volumes and organs at risk in individual patients were delineated. All patients received one fraction of IMRT daily for 5 consecutive days per week. The prescribed radiation doses for all patients were 69.96-74.09 Gy at 2.12-2.39 Gy/ fraction for 29-33 fractions to the planning target volume (PTV) of GTVnx (primary nasopharyngeal gross tumor volume) and GTVnd (involving cervical lymph nodes), which were 60-65.1 Gy to the PTV of CTV1 (high-risk regions), and 51.62-57.6Gy to the PTV of CTV2 (low-risk regions and neck nodal regions).

\section{Chemotherapy}

In addition, 90.2\% (561/622) of patients received neoadjuvant chemotherapy, concurrent or adjuvant chemotherapy. The neoadjuvant chemotherapy consisted of two or three cycles of both docetaxel $\left(60 \mu \mathrm{g} / \mathrm{m}^{2}\right)$, cisplatin $\left(60 \mu \mathrm{g} / \mathrm{m}^{2}\right)$ on day 1 and 5-fluorouracil (600 $\mu \mathrm{g} / \mathrm{m}^{2} /$ day) by continuously intravenous infusion for 5 consecutive days or docetaxel $\left(75 \mu \mathrm{g} / \mathrm{m}^{2}\right)$ and cisplatin $\left(80 \mu \mathrm{g} / \mathrm{m}^{2}\right)$ every three weeks. During the course of radiotherapy, the patients were treated with cisplatin (100 $\mu \mathrm{g} / \mathrm{m}^{2}$ ) every three weeks or $40 \mu \mathrm{g} / \mathrm{m}^{2} /$ week as concurrent chemotherapy. Adjuvant chemotherapy included two or three cycles of cisplatin $\left(80 \mu \mathrm{g} / \mathrm{m}^{2}\right)$ on day 1 and 5-fluorouracil $\left(750 \mu \mathrm{g} / \mathrm{m}^{2}\right)$ daily for 4 consecutive days every four weeks.

\section{Follow-up}

The patients were followed up every 3 months during the first 2 years, every 6 months for the next 
3 years, and then annually thereafter until death. The OS, DMFS, LRFS and PFS of patients were recorded.

\section{Statistical analysis}

The statistical analyses were performed using the statistical package SPSS 16.0 (SPSS, Chicago, IL, USA). Patients were stratified, according to the levels of blood $\mathrm{Hb}$, PLT and serum LDH, as previous descriptions [53-55]. Serum ALB and SF were analyzed as a binary variable using ROC curves to determine their cut-off values. When the area under the curve was the largest, the corresponding number was the cut-off value. The difference in the frequency of each group in individual category was analyzed by the Chi-square test. The survival of each group of patients was estimated by the Kaplan-Meier method and analyzed by the log-rank test. Individual risk factors for the DM of NPC in those patients were determined by univariate and multivariate analyses using the Cox regression model, including the hazard ratios (HR) and $95 \%$ confidence interval $(95 \% \mathrm{CI})$. A two-sided $P$-value of $<0.05$ was considered statistically significant.

\section{Abbreviations}

DM, distant metastasis; NPC, nasopharyngeal carcinoma; IMRT, intensity-modulated radiotherapy; OS, overall survival; DMFS, distant metastasis-free survival; LRFS, local recurrence-free survival; PFS, progressionfree survival; UICC/AJCC, Union for International Cancer Control/ American Joint Committee on Cancer; $\mathrm{ALB}$, albumin; SF, serum ferritin; $\mathrm{Hb}$, hemoglobin; $\mathrm{LDH}$, lactate dehydrogenase; PLT, platelet; PTV, planning target volume; ROC, receiver operating characteristic; HR, hazard ratios.

\section{Author contributions}

XQ designed the study, analyzed data and wrote the manuscript. XF wrote the manuscript. HL, ZG, LL and SQ collected data. XD designed the study and interpreted the findings. All authors read and approved the final manuscript.

\section{ACKNOWLEDGMENTS}

We thank Ms. Ying Chen at the Department of Administration at the Office of Disease Processing of Cancer Hospital for her assistance in collection of patients' follow-up data.

\section{CONFLICTS OF INTEREST}

All authors state no conflicts of interest.

\section{FUNDING}

This work was supported by grants from the Development of Scientific Research and Technology Project of Guangxi Province (Grant Number: 159801222) and the Major Scientific Research Funding Project of Higher Education in Guangxi Province (Grant Number: 201101ZD004).

\section{REFERENCES}

1. Zhang LF, Li YH, Xie SH, Ling W, Chen SH, Liu Q, Huang $\mathrm{QH}$, Cao SM. Incidence trend of nasopharyngeal carcinoma from 1987 to 2011 in Sihui County, Guangdong Province, South China: an age-period-cohort analysis. Chin J Cancer. 2015; 34:350-57.

2. Yong SK, Ha TC, Yeo MC, Gaborieau V, McKay JD, Wee J. Associations of lifestyle and diet with the risk of nasopharyngeal carcinoma in Singapore: a case-control study. Chin J Cancer. 2017; 36:3.

3. Zeng L, Tian YM, Sun XM, Huang Y, Chen CY, Han F, Liu S, Lan M, Guan Y, Deng XW, Lu TX. Intensity-modulated radiotherapy for stage IVA/IVB nasopharyngeal carcinoma: clinical outcomes and patterns of failure in an endemic area in China. Strahlenther Onkol. 2014; 190:993-1000.

4. Jiang F, Jin T, Feng XL, Jin QF, Chen XZ. Longterm outcomes and failure patterns of patients with nasopharyngeal carcinoma staged by magnetic resonance imaging in intensity-modulated radiotherapy era: The Zhejiang Cancer Hospital's experience. J Cancer Res Ther. 2015; 11:C179-84.

5. Wang J, Shi M, Hsia Y, Luo S, Zhao L, Xu M, Xiao F, Fu $\mathrm{X}$, Li J, Zhou B, Long X. Failure patterns and survival in patients with nasopharyngeal carcinoma treated with intensity modulated radiation in Northwest China: a pilot study. Radiat Oncol. 2012; 7:2.

6. Ng WT, Lee MC, Hung WM, Choi CW, Lee $\mathrm{KC}$, Chan OS, Lee AW. Clinical outcomes and patterns of failure after intensity-modulated radiotherapy for nasopharyngeal carcinoma. Int J Radiat Oncol Biol Phys. 2011; 79:420-28.

7. Sun X, Su S, Chen C, Han F, Zhao C, Xiao W, Deng $\mathrm{X}$, Huang S, Lin C, Lu T. Long-term outcomes of intensity-modulated radiotherapy for 868 patients with nasopharyngeal carcinoma: an analysis of survival and treatment toxicities. Radiother Oncol. 2014; 110:398-403.

8. Yue D, Xu YF, Zhang F, Lin L, Mao YP, Li WF, Chen L, Sun Y, Liu LZ, Lin AH, Li L, Ma J. Is replacement of the supraclavicular fossa with the lower level classification based on magnetic resonance imaging beneficial in nasopharyngeal carcinoma? Radiother Oncol. 2014; 113:108-14.

9. Lee N, Harris J, Garden AS, Straube W, Glisson B, Xia P, Bosch W, Morrison WH, Quivey J, Thorstad W, Jones $\mathrm{C}$, Ang KK. Intensity-modulated radiation therapy with 
or without chemotherapy for nasopharyngeal carcinoma: radiation therapy oncology group phase II trial 0225 . J Clin Oncol. 2009; 27:3684-90.

10. Su SF, Han F, Zhao C, Huang Y, Chen CY, Xiao WW, Li JX, Lu TX. Treatment outcomes for different subgroups of nasopharyngeal carcinoma patients treated with intensitymodulated radiation therapy. Chin J Cancer. 2011; 30:565-73.

11. Li AC, Xiao WW, Shen GZ, Wang L, Xu AA, Cao YQ, Huang SM, Lin CG, Han F, Deng XW, Zhao C. Distant metastasis risk and patterns of nasopharyngeal carcinoma in the era of IMRT: long-term results and benefits of chemotherapy. Oncotarget. 2015; 6:24511-21. https://doi. org/10.18632/oncotarget.4312

12. Muliawati Y, Haroen H, Rotty LW. Cancer anorexia cachexia syndrome. Acta Med Indones. 2012; 44:154-62.

13. Lis CG, Gupta D, Lammersfeld CA, Markman M, Vashi PG. Role of nutritional status in predicting quality of life outcomes in cancer-a systematic review of the epidemiological literature. Nutr J. 2012; 11:27.

14. Wang HY, Chang YL, To KF, Hwang JS, Mai HQ, Feng YF, Chang ET, Wang CP, Kam MK, Cheah SL, Lee M, Gao L, Zhang HZ, et al. A new prognostic histopathologic classification of nasopharyngeal carcinoma. Chin J Cancer. 2016; 35:41.

15. Bauer J, Capra S. Comparison of a malnutrition screening tool with subjective global assessment in hospitalised patients with cancer - sensitivity and specificity. Asia Pac J Clin Nutr. 2003; 12:257-60.

16. McMillan DC, Watson WS, O'Gorman P, Preston T, Scott HR, McArdle CS. Albumin concentrations are primarily determined by the body cell mass and the systemic inflammatory response in cancer patients with weight loss. Nutr Cancer. 2001; 39:210-13.

17. Tanriverdi O, Avci N, Oktay E, Kalemci S, Pilanci KN, Cokmert S, Menekse S, Kocar M, Sen CA, Akman T, Ordu C, Goksel G, Meydan N, Barutca S. Pretreatment Serum Albumin Level is an Independent Prognostic Factor in Patients with Stage IIIB Non-Small Cell Lung Cancer: A Study of the Turkish Descriptive Oncological Researches Group. Asian Pac J Cancer Prev. 2015; 16:5971-76.

18. Han S, Huang Y, Li Z, Hou H, Wu A. The prognostic role of preoperative serum albumin levels in glioblastoma patients. BMC Cancer. 2015; 15:108.

19. Tao CJ, Chen YY, Jiang F, Feng XL, Jin QF, Jin T, Piao YF, Chen XZ. The C-reactive Protein/Albumin Ratio Is an independent Prognostic Factor for Overall Survival in Patients with Nasopharyngeal Carcinoma Receiving Intensity-Modulated Radiotherapy. J Cancer. 2016; 7:2005-11.

20. Zhang Y, Zhou GQ, Liu X, Chen L, Li WF, Tang LL, Liu Q, Sun Y, Ma J. Exploration and Validation of C-Reactive Protein/Albumin Ratio as a Novel Inflammation-Based Prognostic Marker in Nasopharyngeal Carcinoma. J Cancer. 2016; 7:1406-12.
21. Wang SL, Cao S, Wu R, Chi F, Tang MY, Jin XY, Chen $\mathrm{XD}$. Serum ferritin predicted prognosis in patients with locally advanced pancreatic cancer. Future Oncol. 2015; 11:2905-10.

22. Shi HB, Li XD, Jiang JT, Zhao WQ, Ji M, Wu CP. Serum ferritin is elevated in advanced non-small cell lung cancer patients and is associated with efficacy of platinum-based chemotherapy. J Cancer Res Ther. 2014; 10:681-85.

23. Facciorusso A, Del Prete V, Antonino M, Neve V, Crucinio N, Di Leo A, Carr BI, Barone M. Serum ferritin as a new prognostic factor in hepatocellular carcinoma patients treated with radiofrequency ablation. J Gastroenterol Hepatol. 2014; 29:1905-10.

24. Petekkaya I, Aksoy S, Roach EC, Okoh AK, Gecmez G, Gezgen G, Isler DC, Dogan E, Babacan T, Sarici F, Petekkaya E, Altundag K. Impact of inflammatory markers on the prognosis of patients with operable breast cancer. $\mathrm{J}$ BUON. 2014; 19:673-80.

25. Ho S, Leung SF, Leung WT, Tsao SY, Kwan WH, Choi P, Johnson PJ. Strong association between hyperferritinaemia and metastatic disease in nasopharyngeal carcinoma. Eur $\mathrm{J}$ Cancer B Oral Oncol. 1996; 32B:242-45.

26. Peng G, Wang T, Yang KY, Zhang S, Zhang T, Li Q, Han $\mathrm{J}, \mathrm{Wu}$ G. A prospective, randomized study comparing outcomes and toxicities of intensity-modulated radiotherapy vs. conventional two-dimensional radiotherapy for the treatment of nasopharyngeal carcinoma. Radiother Oncol. 2012; 104:286-93.

27. Lai SZ, Li WF, Chen L, Luo W, Chen YY, Liu LZ, Sun Y, Lin AH, Liu MZ, Ma J. How does intensitymodulated radiotherapy versus conventional twodimensional radiotherapy influence the treatment results in nasopharyngeal carcinoma patients? Int J Radiat Oncol Biol Phys. 2011; 80:661-68.

28. Leung TW, Tung SY, Sze WK, Wong FC, Yuen KK, Lui CM, Lo SH, Ng TY, O SK. Treatment results of 1070 patients with nasopharyngeal carcinoma: an analysis of survival and failure patterns. Head Neck. 2005; 27:555-65.

29. Li JX, Huang SM, Wen BX, Lu TX. Prognostic factors on overall survival of newly diagnosed metastatic nasopharyngeal carcinoma. Asian Pac J Cancer Prev. 2014; 15:3169-73.

30. Wang W, Feng M, Fan Z, Li J, Lang J. Clinical outcomes and prognostic factors of 695 nasopharyngeal carcinoma patients treated with intensity-modulated radiotherapy. Biomed Res Int. 2014; 2014:814948. https://doi. org/10.1155/2014/814948.

31. Wong FC, Ng AW, Lee VH, Lui CM, Yuen KK, Sze WK, Leung TW, Tung SY. Whole-field simultaneous integratedboost intensity-modulated radiotherapy for patients with nasopharyngeal carcinoma. Int J Radiat Oncol Biol Phys. 2010; 76:138-45.

32. Cao CN, Luo JW, Gao L, Yi JL, Huang XD, Wang K, Zhang SP, Qu Y, Li SY, Cai WM, Xiao JP, Zhang Z, Xu GZ. 
Clinical outcomes and patterns of failure after intensitymodulated radiotherapy for T4 nasopharyngeal carcinoma. Oral Oncol. 2013; 49:175-81.

33. Gupta D, Lis CG. Pretreatment serum albumin as a predictor of cancer survival: a systematic review of the epidemiological literature. Nutr J. 2010; 9:69.

34. Siddiqui A, Heinzerling J, Livingston EH, Huerta S. Predictors of early mortality in veteran patients with pancreatic cancer. Am J Surg. 2007; 194:362-66.

35. Oñate-Ocaña LF, Aiello-Crocifoglio V, Gallardo-Rincón D, Herrera-Goepfert R, Brom-Valladares R, Carrillo JF, Cervera E, Mohar-Betancourt A. Serum albumin as a significant prognostic factor for patients with gastric carcinoma. Ann Surg Oncol. 2007; 14:381-89.

36. Chen Z, Shao Y, Wang K, Cao W, Xiong Y, Wu R, Luo S, $\mathrm{Xu} \mathrm{X}, \mathrm{He} \mathrm{X}$. Prognostic role of pretreatment serum albumin in renal cell carcinoma: a systematic review and metaanalysis. Onco Targets Ther. 2016; 9:6701-10.

37. Li G, Gao J, Liu ZG, Tao YL, Xu BQ, Tu ZW, Zhang XP, Zeng MS, Xia YF. Influence of pretreatment ideal body weight percentile and albumin on prognosis of nasopharyngeal carcinoma: long-term outcomes of 512 patients from a single institution. Head Neck. 2014; 36:660-66.

38. Guagnozzi D, Severi C, Ialongo P, Viscido A, Patrizi F, Testino G, Vannella L, Labriola R, Strom R, Caprilli R. Ferritin as a simple indicator of iron deficiency in anemic IBD patients. Inflamm Bowel Dis. 2006; 12:150-51.

39. Anttila R, Cook JD, Siimes MA. Body iron stores decrease in boys during pubertal development: the transferrin receptor-ferritin ratio as an indicator of iron status. Pediatr Res. 1997; 41:224-28.

40. Vijayavel K, Downs CA, Ostrander GK, Richmond RH. Oxidative DNA damage induced by iron chloride in the larvae of the lace coral Pocillopora damicornis. Comp Biochem Physiol C Toxicol Pharmacol. 2012; 155:275-80.

41. Prá D, Bortoluzzi A, Müller LL, Hermes L, Horta JA, Maluf SW, Henriques JA, Fenech M, Franke SI. Iron intake, red cell indicators of iron status, and DNA damage in young subjects. Nutrition. 2011; 27:293-97.

42. Good MF, Powell LW, Halliday JW. Iron status and cellular immune competence. Blood Rev. 1988; 2:43-49.

43. Weinberg JB, Hibbs JB Jr. Endocytosis of red blood cells or haemoglobin by activated macrophages inhibits their tumoricidal effect. Nature. 1977; 269:245-47.

44. Qin Z, Blankenstein T. CD4+ T cell-mediated tumor rejection involves inhibition of angiogenesis that is dependent on IFN gamma receptor expression by nonhematopoietic cells. Immunity. 2000; 12:677-86.
45. Shah W, Yan X, Jing L, Zhou Y, Chen H, Wang Y. A reversed $\mathrm{CD} 4 / \mathrm{CD} 8$ ratio of tumor-infiltrating lymphocytes and a high percentage of CD4(+)FOXP3(+) regulatory $\mathrm{T}$ cells are significantly associated with clinical outcome in squamous cell carcinoma of the cervix. Cell Mol Immunol. $2011 ; 8: 59-66$.

46. Walker EM Jr, Walker SM. Effects of iron overload on the immune system. Ann Clin Lab Sci. 2000; 30:354-65.

47. Xu T, Huang Z, Su B, Wang S, Wang D, Wang C, Wei W, Jiang J, Zhang G, Yang H, Hu W. Prognostic significance of circulating CD19+ B lymphocytes in EBV-associated nasopharyngeal carcinoma. Med Oncol. 2014; 31:198.

48. Lin JC, Chen KY, Wang WY, Jan JS, Liang WM, Tsai CS, Wei YH. Detection of Epstein-Barr virus DNA in the peripheral-blood cells of patients with nasopharyngeal carcinoma: relationship to distant metastasis and survival. J Clin Oncol. 2001; 19:2607-15.

49. Tao CJ, Chen YY, Jiang F, Feng XL, Jin QF, Jin T, Piao YF, Chen XZ. A prognostic model combining CD4/CD8 ratio and $\mathrm{N}$ stage predicts the risk of distant metastasis for patients with nasopharyngeal carcinoma treated by intensity modulated radiotherapy. Oncotarget. 2016; 7:46653-61. https://doi.org/10.18632/oncotarget.9695

50. Wang W, Knovich MA, Coffman LG, Torti FM and Torti SV. Serum ferritin: Past, present and future. Biochim Biophys Acta. 2010; 1800:760-769.

51. Pontiroli AE, Benetti A, Folini L, Merlotti C, Frigè F. Other aspects of bariatric surgery: liver steatosis, ferritin and cholesterol metabolism. Nutr Hosp. 2013; 28:104-08.

52. Atilla E, Toprak SK, Demirer T. Current Review of Iron Overload and Related Complications in Hematopoietic Stem Cell Transplantation. Turk J Haematol. 2017; 34:1-9.

53. Zhou GQ, Tang LL, Mao YP, Chen L, Li WF, Sun Y, Liu LZ, Li L, Lin AH, Ma J. Baseline serum lactate dehydrogenase levels for patients treated with intensitymodulated radiotherapy for nasopharyngeal carcinoma: a predictor of poor prognosis and subsequent liver metastasis. Int J Radiat Oncol Biol Phys. 2012; 82:e359-65.

54. Jin Y, Cai XY, Cai YC, Cao Y, Xia Q, Tan YT, Jiang WQ, Shi YX. To build a prognostic score model containing indispensible tumour markers for metastatic nasopharyngeal carcinoma in an epidemic area. Eur J Cancer. 2012; 48:882-88.

55. Gao J, Zhang HY, Xia YF. Increased platelet count is an indicator of metastasis in patients with nasopharyngeal carcinoma. Tumour Biol. 2013; 34:39-45. 